\section{Pacific Northwest}

National Laboratory

Operated by Battelle for the

U.S. Department of Energy

\section{Stabilizing $\mathrm{CO}_{2}$ Concentrations with Incomplete International Cooperation}

October 2007

Prepared for the U.S. Department of Energy under Contract DE-AC05-76RL01830 


\section{DISCLAIMER}

This report was prepared as an account of work sponsored by an agency of the United States Government. Neither the United States Government nor any agency thereof, nor Battelle Memorial Institute, nor any of their employees, makes any warranty, express or implied, or assumes any legal liability or responsibility for the accuracy, completeness, or usefulness of any information, apparatus, product, or process disclosed, or represents that its use would not infringe privately owned rights. Reference herein to any specific commercial product, process, or service by trade name, trademark, manufacturer, or otherwise does not necessarily constitute or imply its endorsement, recommendation, or favoring by the United States Government or any agency thereof, or Battelle Memorial Institute. The views and opinions of authors expressed herein do not necessarily state or reflect those of the United States Government or any agency thereof.

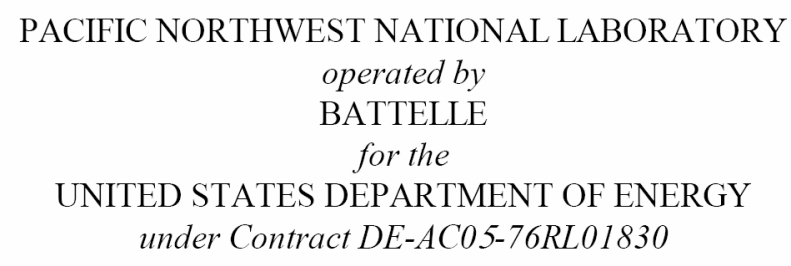

Printed in the United States of America

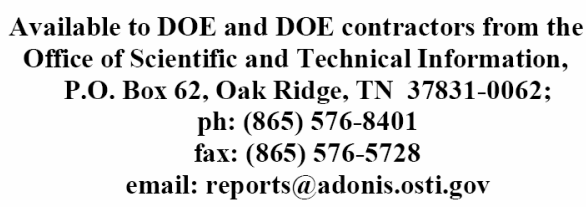

Available to the public from the National Technical Information Service, U.S. Department of Commerce, 5285 Port Royal Rd., Springfield, VA 22161 ph: (800) 553-6847 fax: (703) 605-6900

email: orders@ntis.fedworld.gov

online ordering: http://www.ntis.gov/ordering.htm

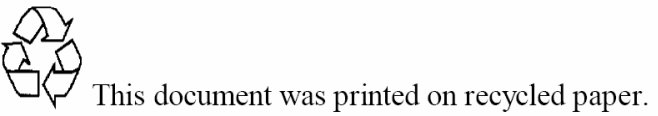




\title{
Stabilizing $\mathrm{CO}_{2}$ Concentrations with Incomplete International Cooperation
}

\author{
JA Edmonds \\ LE Clarke \\ MA Wise \\ JP Lurz
}

Prepared for

the U.S. Department of Energy

under Contract DE-AC05-76RL01830

October 2007

Pacific Northwest National Laboratory

Richland, Washington 99352 



\begin{abstract}
Many stabilization scenarios have examined the implications of stabilization on the assumption that all regions and all sectors of all of the world's economies undertake emissions mitigations wherever and whenever it is cheapest to do so. This idealized assumption is just one of many ways in which emissions mitigation actions could play out globally, but not necessarily the most likely. This paper explores the implications of generic policy regimes that lead to stabilization of $\mathrm{CO}_{2}$ concentrations under conditions in which non-Annex 1 regions delay emissions reductions and in which carbon prices vary across participating regions. The resulting stabilization scenarios are contrasted with the idealized results. Delays in the date by which non-Annex I regions begin to reduce emissions raise the price of carbon in Annex I regions relative to the price of carbon in Annex $\mathrm{I}$ in an idealized regime for any given $\mathrm{CO}_{2}$ concentration limit. This effect increases the longer the delay in non-Annex I accession, the lower the non-Annex 1 carbon prices relative to the Annex 1 prices, and the more stringent the stabilization level. The effect of delay is very pronounced when $\mathrm{CO}_{2}$ concentrations are stabilized at $450 \mathrm{ppmv}$, however the effect is much less pronounced at 550 ppmv and above. For long delays in non-Annex I accession, 450 ppmv stabilization levels become infeasible.
\end{abstract}





\section{Acknowledgements}

The authors are indebted to the U.S. Department of Energy's Office of Science and to the Electric Power Research Institute for financial support for this research. The authors are also indebted to several individuals for comments on an earlier version of this work, including Richard Richels, Tom Rutherford, Geoff Blanford, and Richard Moss. 



\section{Contents}

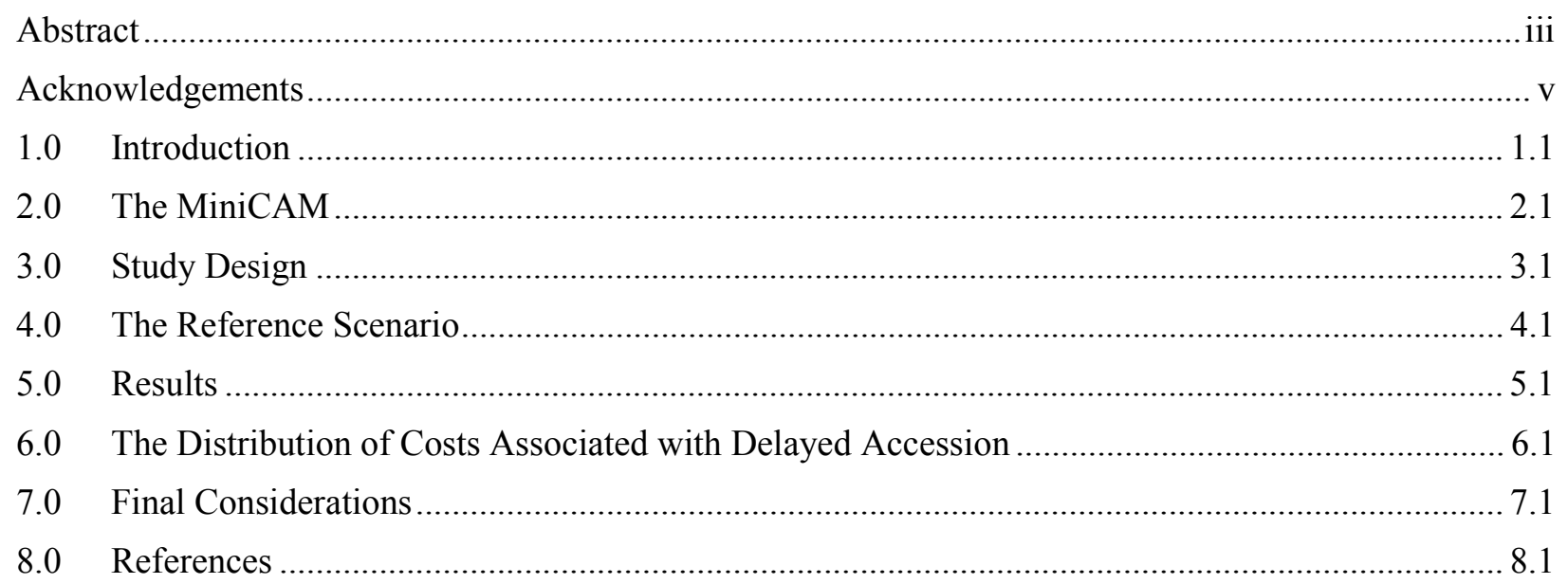




\section{Figures}

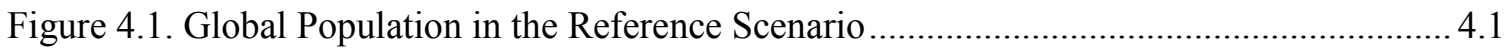

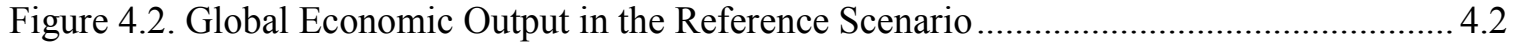

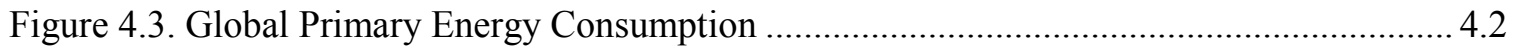

Figure 4.4. Global Fossil Fuel and Industrial Carbon Emissions by Region 2005 to 2095 .......... 4.2

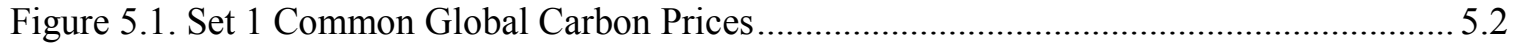

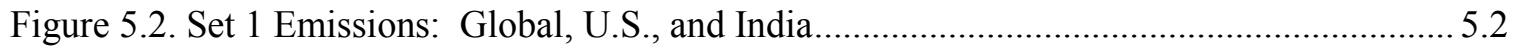

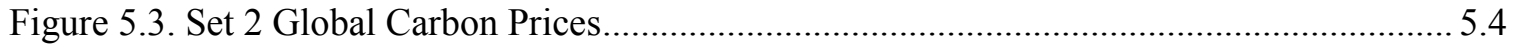

Figure 5.4. Set 2 Stabilization at 650 ppmv—Global, U.S., and India Emissions.......................... 5.4

Figure 5.5. Set 2 Stabilization at 550 ppmv - Global, U.S., and India Emissions........................ 5.5

Figure 5.6. Set 2 Stabilization at 450 ppmv - Global, U.S., and India Emissions........................5.5

Figure 5.7. Set 3 Regional Carbon Prices 650 ppmv - Annex 1 and India................................... 5.6

Figure 5.8. Set 3 Regional Carbon Prices 550 ppmv - Annex 1 and India................................... 5.6

Figure 5.9. Set 3 Regional Carbon Prices 450 ppmv - Annex 1 and India................................... 5.7

Figure 5.10. Set 3 Stabilization at 650 ppmv-Global, U.S., and India Emissions......................5.7

Figure 5.11. Set 3 Stabilization at 550 ppmv—Global, U.S., and India Emissions......................5.8

Figure 5.12. Set 3 Stabilization at 450 ppmv—Global, U.S., and India Emissions......................5.8

\section{Tables}

Table 3.1. Summary of Three Alternative Sets of Hypothetical Policy Regimes.......................... 3.2

Table 6.1. Percentage Increase in Total Social Cost of Stabilization at Alternative Levels of

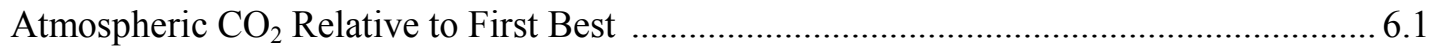

Table 6.2. Fraction of Total Social Cost of Stabilization at Alternative Levels of Atmospheric $\mathrm{CO}_{2}$

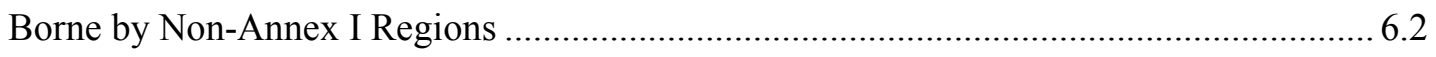




\subsection{Introduction}

Ultimately, the atmospheric concentration of $\mathrm{CO}_{2}$ must be stabilized to limit climate change. To understand the energy, economic, emissions, and other implications of stabilization, researchers have been creating economic, computer-based global stabilization scenarios for over two decades (see, for example, Edmonds and Reilly, 1985). Traditionally, these stabilization scenarios have examined the implications of stabilizing greenhouse gas concentrations under the first-best assumptions of perfect "where" and "when" flexibility; that is, all regions of the world and all sectors of all of the world's economies undertake emissions reductions wherever and whenever it is cheapest to do so (see, for example, IPCC 2001 and Clarke et al., 2007a). Examination of the first-best policy scenario is attractive because it is unique and well defined. However, it is unlikely that the world will undertake to address climate change in such a cooperative fashion, and it is therefore important to understand the characteristics and ramifications of non-idealized policy regimes.

One characteristic of the first-best regime is that it minimizes the economic costs of stabilization. To the extent the real world deviates from the first-best world, the global cost of stabilization will be higher. This raises several questions of relevance to the international policy-making process. How much higher are costs under inefficient policies? Which inefficiencies have the largest impacts? What are the regional impacts on mitigation actions and carbon prices? How do these inefficiencies interact with stabilization goals? Unfortunately, there are an infinite number of non-idealized policy regimes, leaving researchers interested in these questions with the difficult task of identifying realistic and meaningful non-idealized policy scenarios for examination.

This paper examines scenarios that stabilize the $\mathrm{CO}_{2}$ concentration at three different levels under generic assumptions that limit "where" and "when" flexibility. This approach contrasts to an alternative approach that considers alternative hypothetical protocols that prescribe emissions mitigation behavior without regard to a particular atmospheric end-state. This approach has been used in a variety of earlier studies, including Richels et al. (1996), Edmonds and Wise (1998), and modeling analyses of the Kyoto Protocol conducted through the Energy Modeling Forum 16 study (Weyant and Hill, 1999). This latter approach can be used to consider options that are under discussion regardless of where these discussions ultimately lead. In contrast, by adding a limit on $\mathrm{CO}_{2}$ concentrations, this paper puts the resulting scenarios on a common footing with respect to the atmospheric end states.

Two types of generic inefficiencies are considered in this paper: (1) inefficiencies in "when" flexibility, namely the year in which regions begin emissions reductions (the date of accession), and (2) inefficiencies in "where" flexibility, namely the degree to which marginal costs of emissions reductions vary across regions that are undertaking emissions reductions. This paper does not consider inefficiencies in emissions mitigation within regions; that topic is reserved for future research.

This paper considers only the implications for emissions mitigation. It does NOT explore the larger issue of stabilization benefits. Clearly, emissions mitigation would not be undertaken without a belief the benefits were at least as large as the costs, and ideally that the marginal benefits from additional mitigation were approximately as large as the marginal costs of emissions mitigation. Therefore, this paper develops only part of the information needed for a region or international community to develop a 
climate policy. It is important to emphasize this study is not a cost-benefit analysis; rather, it is a costeffectiveness analysis.

The remainder of the paper proceeds as follows. Section 2 describes the MiniCAM modeling framework employed in this analysis. Section 3 outlines the three sets of hypothetical and generic international emissions mitigation regimes that are explored for three different concentrations of atmospheric $\mathrm{CO}_{2}: 450$ ppmv, 550 ppmv, and 650 ppmv. Section 4 then describes the reference case which serves as a backdrop against which the stabilization scenarios occurs. Idealized stabilization scenarios assuming first-best policies, i.e. perfect "where" and "when" flexibility, are discussed in Section 5. Carbon prices and emissions reductions at both global and regional levels are discussed. Section 6 explores the impact of inefficiencies on global and regional costs of stabilization and global and regional emissions pathways in more detail. Discussion and conclusions are provided in Section 7. 


\subsection{The MiniCAM}

The analysis in this paper was conducted using the MiniCAM integrated assessment model. MiniCAM (Brenkert et al. 2003, Kim, et al. 2006)) combines a technologically detailed global energyeconomy-agricultural-land-use model with a suite of coupled gas-cycle, climate, and ice-melt models, integrated in the Model for the Assessment of Greenhouse-Gas Induced Climate Change (MAGICC).

The MiniCAM is a direct descendent of a model developed by Edmonds and Reilly (1985). MiniCAM was developed and is maintained at the Joint Global Change Research Institute, a partnership between the Pacific Northwest National Laboratory (PNNL) and the University of Maryland, while MAGICC was developed and is maintained at the National Center for Atmospheric Research (NCAR). MiniCAM is a global model disaggregated into 14 geopolitical regions. It is solved on a 15 -year time step.

MiniCAM has been used extensively for energy, climate, and other environmental analyses conducted for organizations that include the U.S. Department of Energy (DOE), the U.S. Environmental Protection Agency, the Intergovernmental Panel on Climate Change (IPCC), and other government, private and non-governmental organizations. The MiniCAM is designed to examine long-term, largescale changes in global and regional energy systems, focusing on the impact of energy technologies. Documentation for MiniCAM can be found at http://www.globalchange.umd.edu/models/MiniCAM.pdf/.

The scenarios in this paper were conducted using the version of MiniCAM that participated in the U.S. Climate Change Science Program's (CCSP) scenarios of greenhouse gas emissions and concentrations (Clarke, et al. 2007a). Extensive documentation of the assumptions for the models can be found in that document as well as in Clarke et al. (2007b). The reference and stabilization scenarios in this paper vary in one important way from the MiniCAM CCSP scenarios. In those scenarios, the terrestrial carbon cycle interacts with the agriculture and land-use behavior. In this paper, net uptake by terrestrial ecosystems is prescribed. This change was made to simplify the computational environment and to focus on the role of energy and industrial $\mathrm{CO}_{2}$ emissions. 



\subsection{Study Design}

This paper explores the stabilization of atmospheric $\mathrm{CO}_{2}$ concentrations at three alternative levels: 450 ppmv, 550 ppmv, and 650 ppmv. These three stabilization levels are of interest in that they all require significant emissions reductions over the coming century. Each of these was considered against three alternative policy backgrounds denoted as Sets 1,2, and 3. In all of the stabilization scenarios, emissions are limited in such a way that the concentration of $\mathrm{CO}_{2}$ never exceeds the prescribed level. ${ }^{1}$

In all instances, emissions mitigation in each region is achieved through the imposition of a domestic price placed on carbon emissions. It would, alternatively, have been possible to construct hypothesized cap-and-trade international policy structures that would yield essentially the same carbon prices and international distributions of emissions mitigation. However, cap-and-trade regimes require that a distribution of emissions rights be prescribed. Those emissions rights do not affect the emissions mitigation undertaken in each region, assuming minimal transactions costs, but they do create a set of income transfers. Those income transfers depend completely on the emissions distributions. Researchers have explored the implications of alternative regimes in earlier work (see, for example, Edmonds et al. 1993a, 1993b; Rose et al. 1998). The implications of alternative emissions-permit allocations are not the focus of this paper.

The characteristics of the three alternative hypothetical policy regimes, namely Sets 1, 2, and 3, that considered in this paper are summarized in Table 3.1 and described below. Each set of scenarios is assigned a name given in Table 3.1 .

Set 1: First-Best Scenarios. This is the simplest of the hypothetical protocol sets, assuming perfect "where" and "when" flexibility. It serves as a benchmark for exploring the deviations from efficiency explored in Set 2 and Set 3. All regions of the world begin a common program of emissions mitigation in $2012^{2}$, applying a common carbon price to all $\mathrm{CO}_{2}$ emissions in all sectors of their economies: no emissions are exempt. ${ }^{3}$

The price of carbon over time follows a Hotelling-Peck-Wan (HPW) price path ${ }^{4}$. The HPW path is a global, present-discounted-cost-minimizing price path. It has two parts. Along the first part of the path, the price of carbon rises at the rate of interest, plus the in-year average rate of removal of carbon from the atmosphere by ocean and terrestrial carbon sinks. ${ }^{5}$ Therefore, there is an initial price in the first year of emissions mitigation, 2013, which rises exponentially thereafter. The price of carbon is thus initially low, but doubles at a regular rate until the concentration of $\mathrm{CO}_{2}$ reaches the concentration limit. Along any HPW pathway, a decision maker in any period sees the discounted marginal cost of reducing a ton of

\footnotetext{
${ }^{1}$ That is, this paper does not consider "overshoot" scenarios in which the concentration of $\mathrm{CO}_{2}$ temporarily passes above the target level and later declines to a lower final stabilization level. For example, see Kheshgi et al. (2005) or Wigley et al. (2006). The maximum cumulative emissions over 1000 years for any ultimate stabilization level were calculated by Kheshgi et al. (2005). A fuller exploration of the "overshoot" scenarios will be taken up in future work.

${ }^{2}$ Prior to 2012, it is assumed that present policy commitments are successfully implemented. That is, it is assumed that the Kyoto Protocol is implemented by member nations. Similarly, it is assumed that commitments on the part of the U.S. and other regions are also successfully implemented.

${ }^{3}$ Note again that this paper assumes that terrestrial emissions from land use and land-use change remain constant.

${ }^{4}$ See Peck and Wan (1996), which elaborates on the original approach developed by Hotelling (1931).

${ }^{5}$ Note that an average rate of ocean and terrestrial uptake over time was used in these scenarios. In reality, the ocean-atmosphereterrestrial biosphere system is dynamic, so the rate of uptake varies over time and between scenarios.
} 
carbon in the present and future as equal. Therefore, if the initial price of carbon is known, then all subsequent carbon prices are uniquely determined until the concentration of $\mathrm{CO}_{2}$ reaches the ceiling. Note that because the carbon cycle removes some portion of any emissions in the present period by the second period, the rate of price rise must be adjusted upward at the removal rate to compare tons of carbon across time.

Table 3.1. Summary of Three Alternative Sets of Hypothetical Policy Regimes

\begin{tabular}{||l|l|l|l||}
\hline \multicolumn{1}{||}{ Name } & \multicolumn{1}{c|}{$\begin{array}{c}\text { Set 1 } \\
\text { First-Best }\end{array}$} & \multicolumn{1}{c||}{$\begin{array}{c}\text { Set 2 } \\
\text { Graduated Accession }\end{array}$} & \multicolumn{1}{c||}{$\begin{array}{c}\text { Set 3 } \\
\text { Heterogeneous Regimes }\end{array}$} \\
\hline \hline $\begin{array}{l}\mathrm{CO}_{2} \text { Stabilization } \\
\text { Concentrations }\end{array}$ & \multicolumn{3}{c||}{$450,550,650 \mathrm{ppmv}$} \\
\hline Participation & $\begin{array}{l}\text { All regions } \\
\text { participate } \\
\text { beginning in } \\
2012 .\end{array}$ & $\begin{array}{l}\text { All Annex I regions join in 2012. } \\
\text { Non-Annex I regions enter the } \\
\text { international system with the } \\
\text { wealthiest joining in 2020, 2035 } \\
\text { or 2050 (three sub-cases). Other } \\
\text { non-Annex I nations enter when } \\
\text { their per-capita income reaches } \\
\text { the level of the first participating } \\
\text { region when it joined the regime. }\end{array}$ & Same as in Set 2. \\
\hline $\begin{array}{l}\text { Regional Carbon } \\
\text { Price }\end{array}$ & $\begin{array}{l}\text { Follows a } \\
\text { globally } \\
\text { common } \\
\text { HPW path. } \\
\text { participating regions; follows a } \\
\text { HPW path, but only participating } \\
\text { regions charge for emissions. }\end{array}$ & $\begin{array}{l}\text { A common price path for } \\
\text { the initial coalition; each } \\
\text { late entrant follows a } \\
\text { unique price path, based on } \\
\text { their per-capita income } \\
\text { relative to a benchmark per- } \\
\text { capita income, leading } \\
\text { eventually to the global } \\
\text { price. }\end{array}$ \\
\hline HPW = Hotelling-Peck-Wan.
\end{tabular}

When the concentration of $\mathrm{CO}_{2}$ reaches the limit, the price is no longer set by the exponential growth path. At this point, there is a transition to a price path determined by the physical characteristics of the carbon cycle. The physical uptake of terrestrial and ocean carbon reservoirs govern allowable emissions. Global emissions are thereafter controlled so that the concentration of $\mathrm{CO}_{2}$ is held constant at the limit. The price of carbon is set so that allowable emissions are exactly equal to carbon uptake by terrestrial and ocean reservoirs.

The initial price is set such that the exponentially rising price path and the physically constrained price path are continuous at the point of transition. That is, there are no ways of reducing total costs by shifting emissions mitigation between the exponentially growing price regime and concentration maintenance regime by arbitraging at the transition point. The HPW carbon price path defines a cost minimizing emissions mitigation pathway for any $\mathrm{CO}_{2}$ stabilization concentration. 
The economically efficient carbon price today is irrevocably linked to expectations about future technology availability and emissions mitigation. For any $\mathrm{CO}_{2}$ concentration, pessimistic expectations about humanity's ability to mitigate carbon emissions in the far future would be reflected in a higher price of carbon and larger emissions reductions today. Conversely, optimistic expectations about humanity's ability to mitigate carbon emissions in the far future would be reflected in lower carbon prices and less aggressive emissions reductions today. This link between present and future holds at any point of time across the entire course of the stabilization regime. Thus, as information is acquired about the degree of difficulty in achieving emissions mitigation over time, and as expectations about the future are revised, so too must the then current price. Increasing optimism about future costs of emissions mitigation would reduce the then current price of carbon and increasing pessimism would have the opposite effect.

Set 2, the Graduated Accession Stabilization Set, examines the implications of delayed accession to a global regime by non-Annex I regions. This set of scenarios is consistent with the United Nations Framework Convention on Climate Change (United Nations, 1992), which establishes common but differentiated responsibilities for developed and developing countries. Set 2 is similar to the first-best scenarios in that there is a single carbon price, beginning in 2012, for all regions undertaking emissions reductions. The carbon price is assumed to rise at the HPW rate, with an initial price set so that the price time-path is continuous at the moment in time when the atmospheric concentration of $\mathrm{CO}_{2}$ reaches the steady-state value.

The inefficiency occurs because not all regions begin emissions reductions in 2012. Non-Annex I nations join the coalition based on the date of accession of China, whose accession is set by hypothesis to be either the year 2020,2035, or 2050. Other regions join in the period in which their per capita income level is at least a great as China's at its accession. This allows examination of the implication of later accession of non-Annex I nations on Annex I nations.

The scenario can be viewed as consisting of a single coalition of mitigating countries that begins emissions mitigation in 2012 and grows over time, and in which all of the coalition's members share a common carbon price. Hence, perfect "where" flexibility is achieved, but only within the coalition. As more and more regions join the Set 2 coalition, the closer the coalition approaches perfect "where" flexibility globally. Until the final region joins the coalition, the world as a whole does not practice perfect "where" flexibility. However, the Set 2 coalition can never achieve perfect "when" flexibility as the coalition was fragmented at its inception. As will be discussed later, the longer the delay in accession, the higher the price of carbon in the coalition and the greater the economic shock to the region upon accession.

Set 3, the Heterogeneous Regimes Stabilization Set, is similar to Set 2 in that regions join the coalition of emissions mitigating regions based on the assumed accession date for China and on their per capita income relative to China's when it enters the coalition. Set 3 differs from Set 2 in that not all coalition members impose a common carbon price. The initial entrants to the coalition-the Annex I countries - all see a common carbon price. The carbon prices in the late entrants differ, at least initially, from the global price and vary among regions. The carbon price for late entrants relative to the Annex I price is determined by the ratio of each late entrant's per-capita income to the U.S. per-capita income in the first year that China joins the coalition. Hence, each late entrant sees a carbon price that gradually converges to the global level as their per-capita income converges to the benchmark per-capita income. 
Thus, as with Set 2, the coalition can never reach perfect "when" flexibility as the coalition was fragmented at its inception. Further, because some regions do not reach the benchmark per-capita income in the twenty-first century, the world does not achieve perfect "where" flexibility until sometime in the twenty-second century. However, within each region perfect "where" flexibility is assumed to exist. 


\subsection{The Reference Scenario}

The reference scenario for this paper is described in detail in Clarke et al. (2007a and 2007b). Although production from non-emitting energy sources such as nuclear power, bioenergy, and other renewable energy sources increases over the century, this does not forestall increased consumption of fossil fuels and associated $\mathrm{CO}_{2}$ emissions. The scenario is characterized by a transition in population, economic output, and $\mathrm{CO}_{2}$ emissions from the Annex 1 to the non-Annex I regions (Figure 4.1, Figure 4.2, and Figure 4.4). This transition has strong implications for the effects of delayed action on the part of these countries. Clearly, carbon regimes will be most effective if the largest emitters are included in the coalition of countries reducing their emissions.

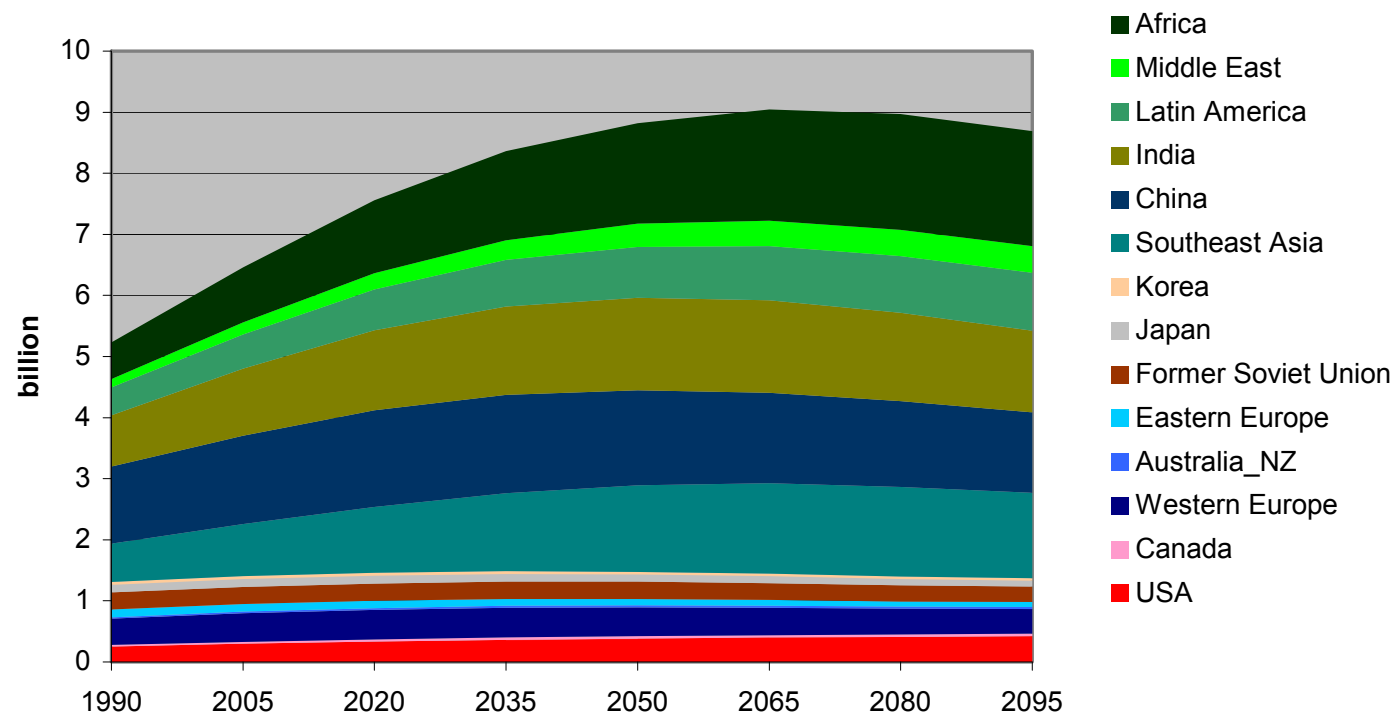

Figure 4.1. Global Population in the Reference Scenario

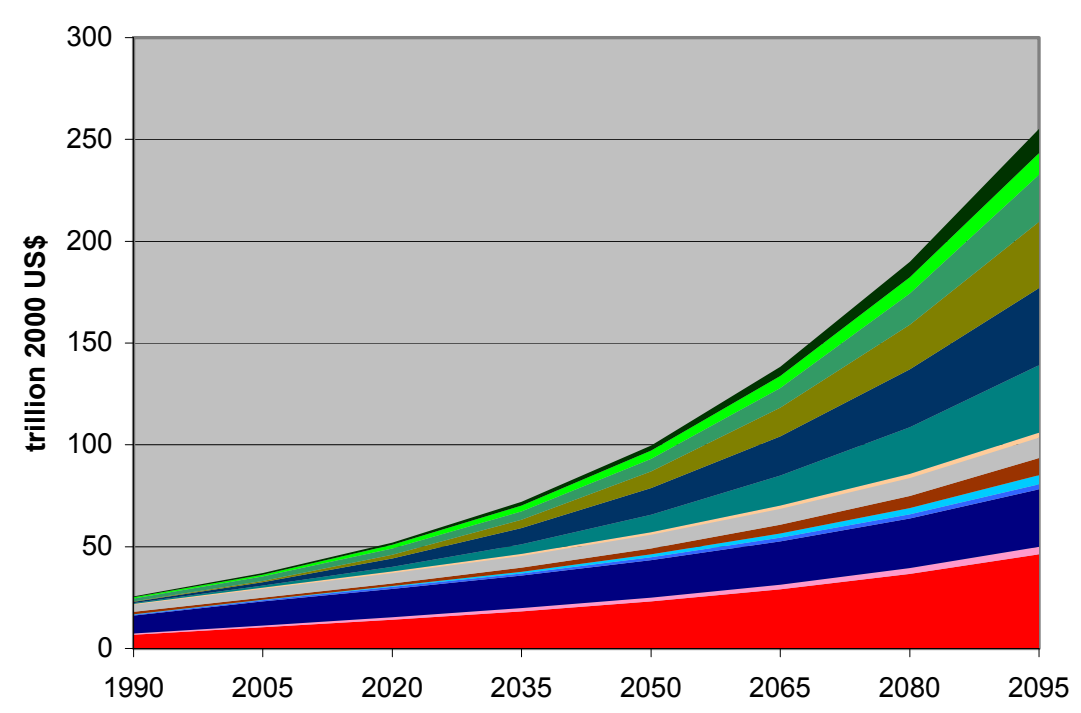

- Africa

Middle East

- Latin America

India

- China

- Southeast Asia

Korea

Japan

- Former Soviet Union

Eastern Europe

- Australia_NZ

- Western Europe

Canada

- USA 
Figure 4.2. Global Economic Output in the Reference Scenario

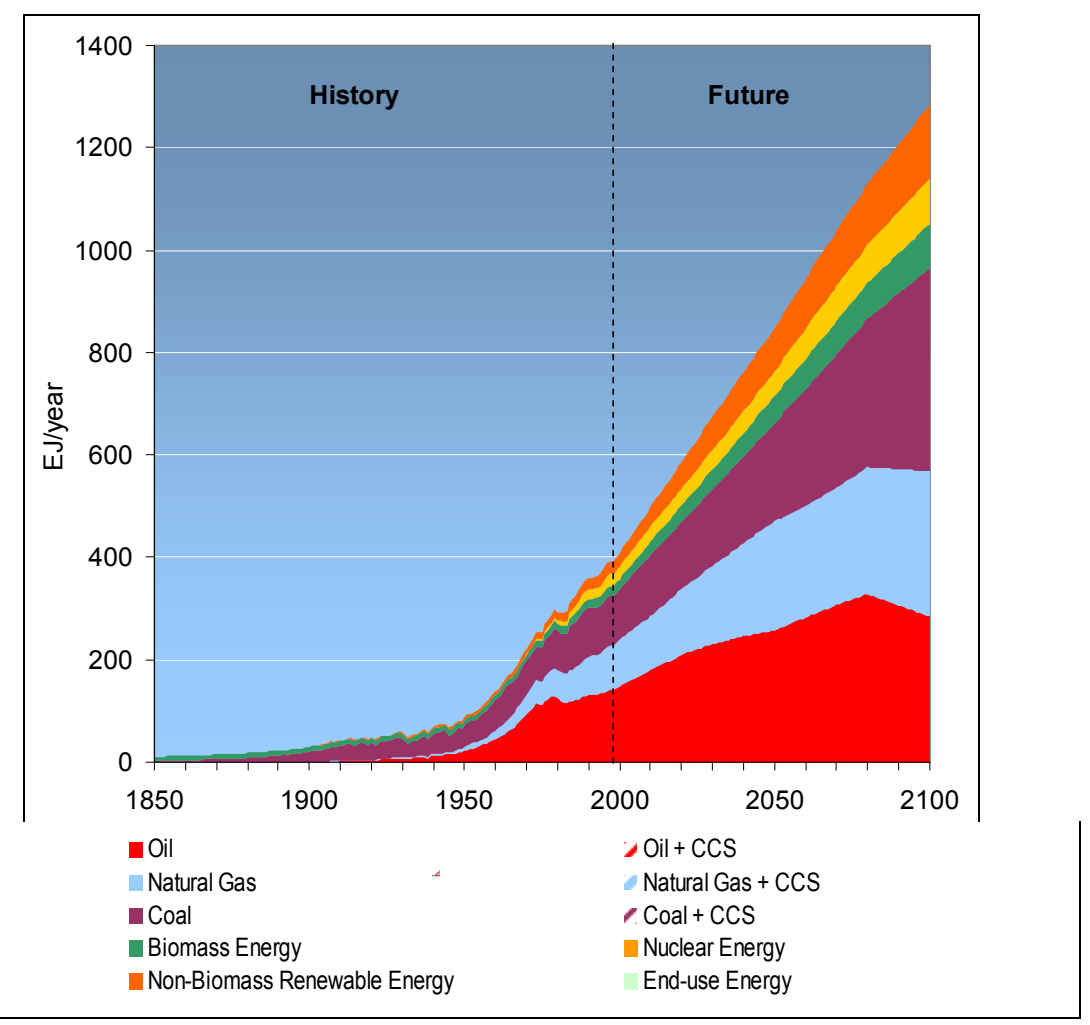

Figure 4.3. Global Primary Energy Consumption

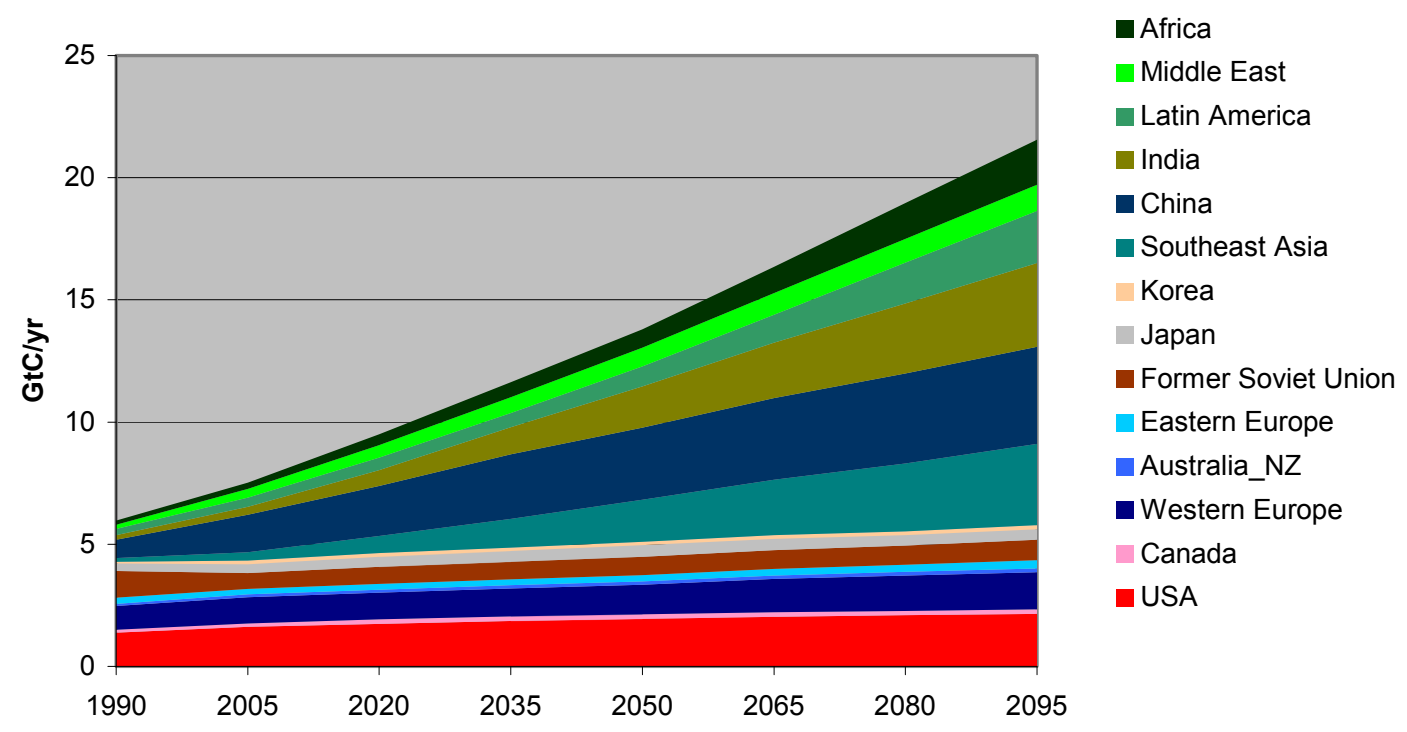

Figure 4.4. Global Fossil Fuel and Industrial Carbon Emissions by Region 2005 to 2095 


\subsection{Results}

This section discusses the results from the three hypothetical stabilization regimes. Results are presented and discussed for the world, the U.S., and India. The U.S. and India are highlighted not because they are more important than other regions of the world, but they are exemplars of the differential impact of the hypothetical protocols.

Set 1: The First-Best Stabilization Set. Although all three first-best scenarios lead to stabilization in the long run, only the $450 \mathrm{ppmv}$ scenario reaches stabilization this century. The $450 \mathrm{ppmv}$ scenario reaches stabilization by 2065, at which point emissions, roughly level out and the carbon price is determined by the allowable emissions for maintaining the $450 \mathrm{ppmv}$ limit (Figure 5.1). Stabilization is not reached until after 2095 for the $550 \mathrm{ppmv}$ and $650 \mathrm{ppmv}$ scenarios, so carbon prices continue to rise exponentially through 2095.

Because stabilization occurs sooner for the 450 ppmv stabilization level, there is less flexibility to distribute emissions reductions over time. The ramification of this lack of flexibility is more aggressive emissions reductions and higher carbon prices in the near term (Figure 5.1). Global emissions begin to decline immediately in the 450 ppmv scenario, whereas global emissions do not begin to decline until after 2050 in the 550 ppmv scenario and after 2065 in the 650 ppmv scenario: emissions track more closely to the reference emissions in the two less stringent scenarios. The price of carbon is a factor of five or more times higher for the $450 \mathrm{ppmv}$ scenario than for the other two first-best stabilization limits. This lack of flexibility will exert a strong influence on the emissions and cost effects of the inefficient policies in Set 2 and Set 3. Delays in emission reductions in the non-Annex 1 countries will have proportionally larger impacts on costs and emissions reductions in the 450 ppmv scenario.

Uniform carbon prices do not imply uniform emissions trajectories, because regions vary in a range of factors that influence the growth in their reference emissions and their opportunities for emissions reductions. If countries such as India and China grow more quickly than the global average, as is the case in these scenarios, then the growth in both their reference emissions and their emissions under stabilization will be higher than the global average as well as developed countries such as the U.S. Hence, emissions decline more quickly in the U.S. than in India across the first-best stabilization scenarios. For example, U.S. emissions decline immediately in the 450 ppmv scenario, whereas Indian emissions continue to grow through 2035. 


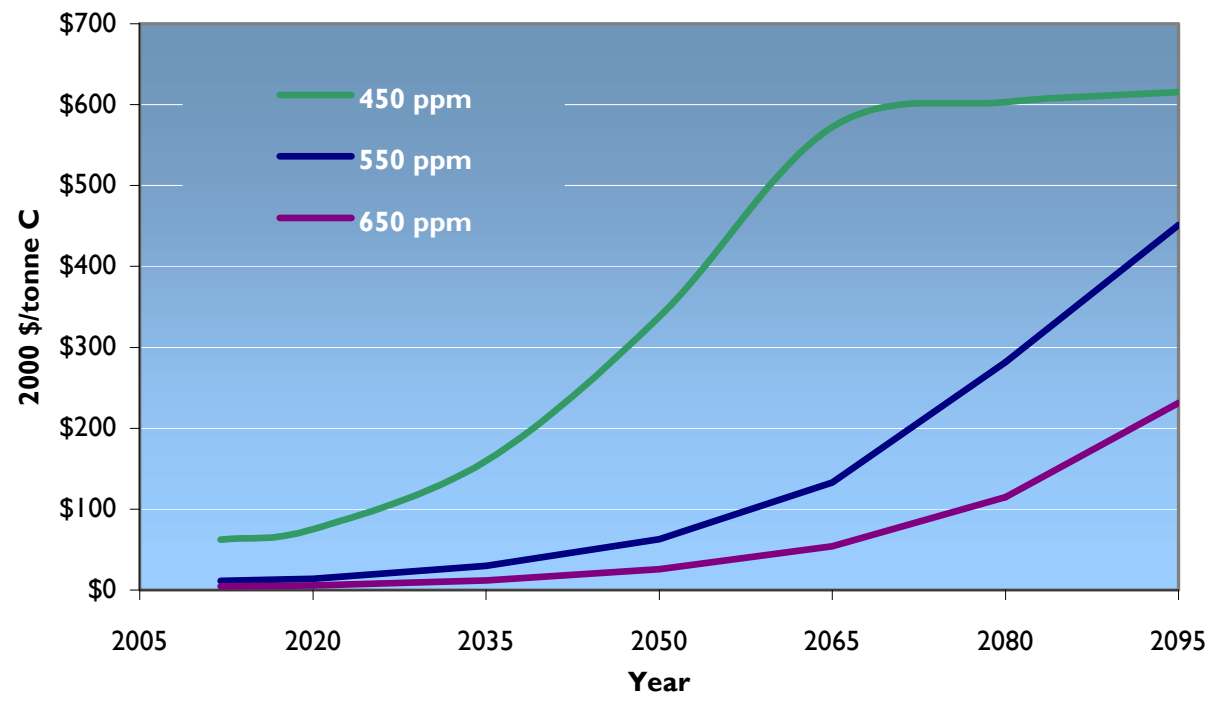

Figure 5.1. Set 1 Common Global Carbon Prices
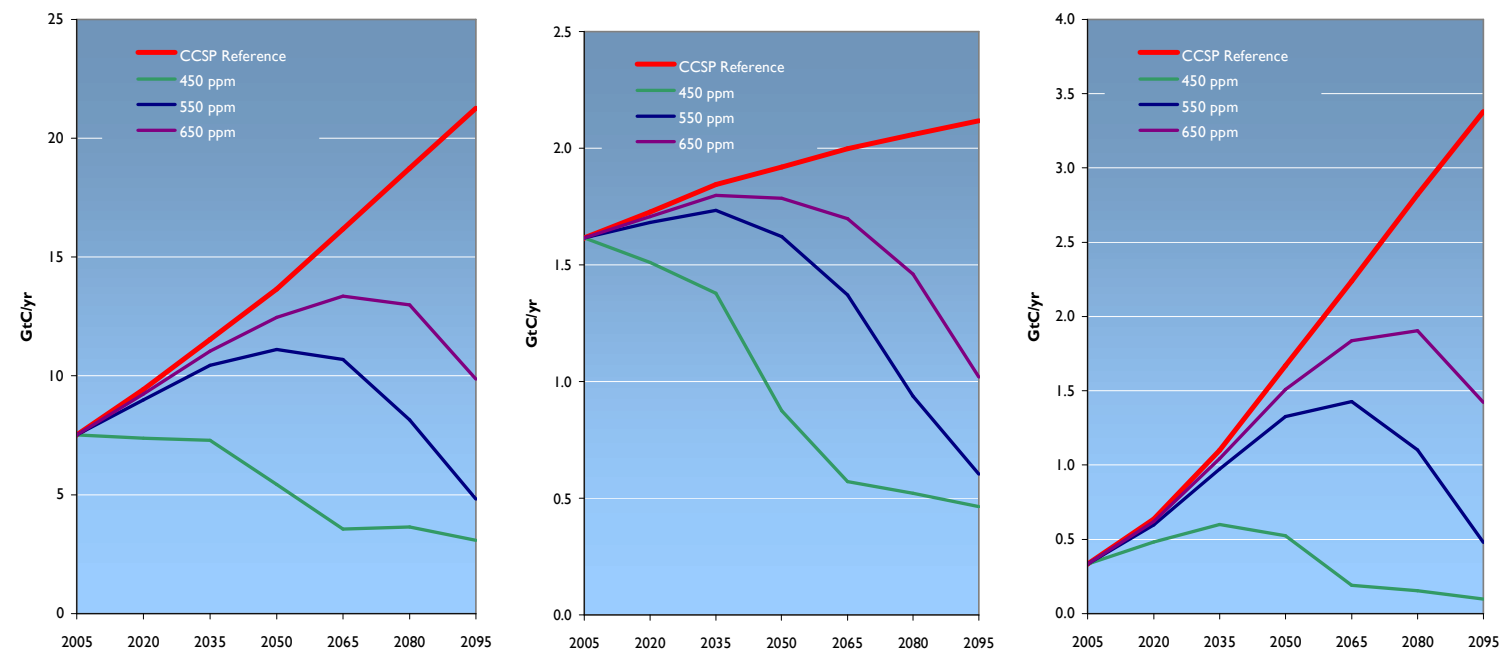

Figure 5.2. Set 1 Emissions: Global, U.S., and India

\section{Set 2: Graduated Accession.}

The effect of delaying the entry of non-Annex 1 countries into the coalition depends crucially on the concentration at which $\mathrm{CO}_{2}$ is stabilized (Figure 5.3 through Figure 5.6). Delays to the year 2020 have only modest impact on the price of carbon that mitigating regions apply to $\mathrm{CO}_{2}$ emissions. If the limit on the concentration of $\mathrm{CO}_{2}$ is $650 \mathrm{ppmv}$, delays, even to mid-century, result in an increase of about 50 percent relative to first-best prices, which assume perfect "where" and "when" flexibility. That same delay roughly doubles the price of carbon when the $\mathrm{CO}_{2}$ concentration is limited to $550 \mathrm{ppmv}$. When the $\mathrm{CO}_{2}$ concentration is limited to 450 ppmv, a delay in non-Annex I region accession until the year 2050 renders the limit infeasible. Delays in non-Annex I accession - even to 2035 - lead to a carbon price that spikes at more than $\$ 2500$ per ton of carbon before declining subsequent to the entry of the largest 
emitting non-Annex I regions. However, that price spike assumes long-term flexibility is available in the short term. As discussed below, U.S. carbon emissions are reduced by approximately half by 2020 , which dramatically alters the result under first-best policy conditions, where U.S. emissions declined by approximately half in 2050. At a global level, the effect of delayed accession is to raise peak emissions somewhat and to reduce emissions more rapidly at the end of the century, though the increase in peak emissions is less than 15 percent in all instances.

Delays in accession of the non-Annex 1 countries put greater pressure on the Annex 1 countries for near-term emissions than under first-best conditions. The severity of the effect depends on the stabilization concentration of $\mathrm{CO}_{2}$. At a concentration of $650 \mathrm{ppmv}$, the effects are relatively modest. They are more pronounced in the Set 2550 ppmv stabilization scenarios. The effect is much larger when the concentration is $450 \mathrm{ppmv}$. The physical limits imposed by the carbon cycle are so strict for the 450 ppmv case that annual global emissions are almost identical in the first-best and Set 2 cases. That means that if a region undertook emissions mitigation in the first-best $450 \mathrm{ppmv}$ case, and does not in a Set 2 case, those first-best emissions mitigations must be made up in Set 2 by participating regions roughly in the first half of the century. This is seen in stark perspective in the Set 2450 ppmv limit with delays in accession to 2035. In this instance, the U.S. emissions are forced to decline by more than 70 percent relative to the reference by 2020 . For the $550 \mathrm{ppmv}$ and $650 \mathrm{ppmv}$ cases, some emissions mitigation is shifted out in time, cushioning the incremental burden on participating regions.

The structure of the regime, i.e., a common emissions mitigation group with a common carbon price (e.g., the Kyoto Protocol), leads to a "carbon price shock" for regions entering the regime late. In this study, delayed accession causes India's emissions to drop precipitously once it joins the coalition. The price of carbon is common and rises with time. The longer India remains outside the coalition, the higher the price rises. As a consequence, India's economy does not experience a gradual, steady increase in the price of carbon. In fact, regions outside the control regime experience declining fossil-fuel prices and therefore have an incentive to increase fossil-fuel use relative to the reference case and therefore have somewhat higher emissions. Thus, late-entering parties experience decades of carbon price increases instantaneously. As a consequence, India's economy experiences the "carbon price shock," which in turn leads to precipitous emissions decline. The long-term nature of the MiniCAM model means that the full economic impact of the price shock is under reported, although it should be noted that the greater India's preparations are for this shock, the effect of the shock will be lower. Nonetheless, the degree of shock experienced is significant and again points to problems in a regime with this characteristic. 

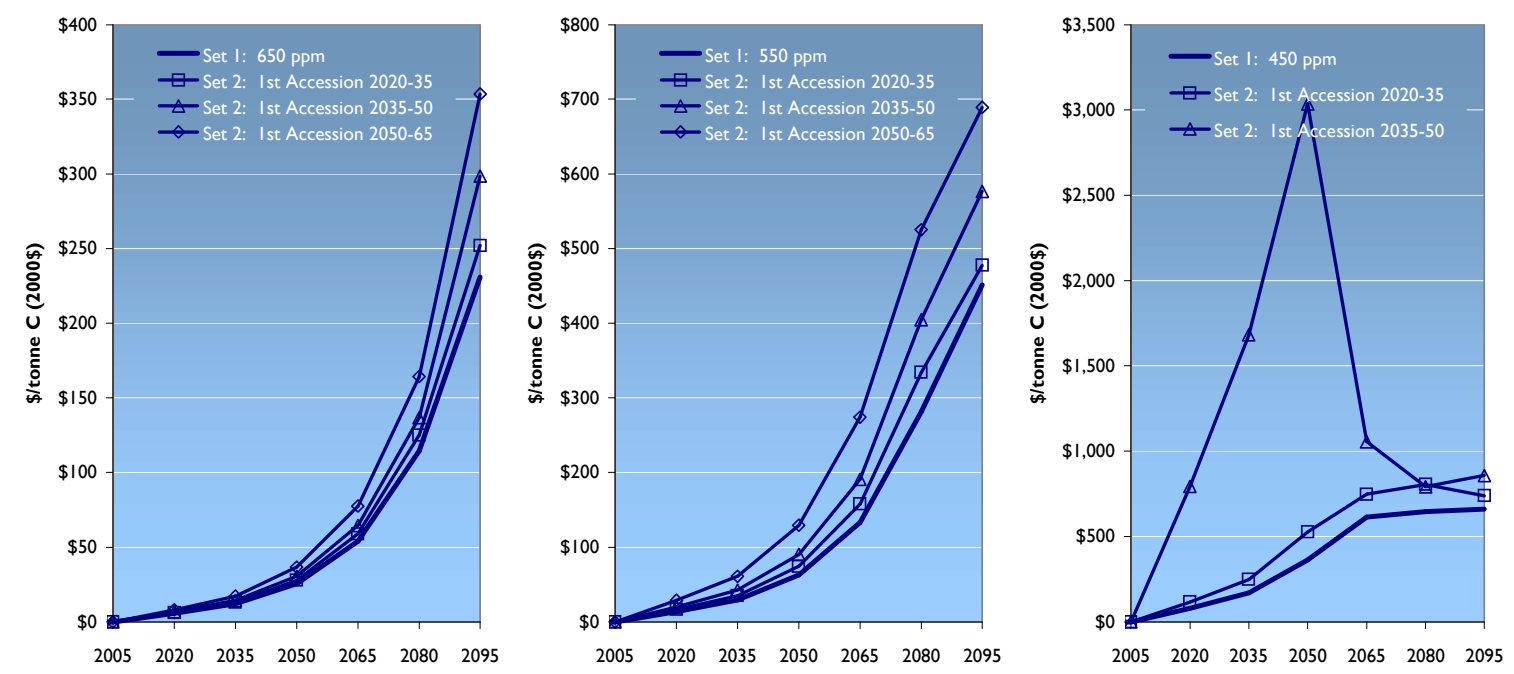

Figure 5.3. Set 2 Global Carbon Prices
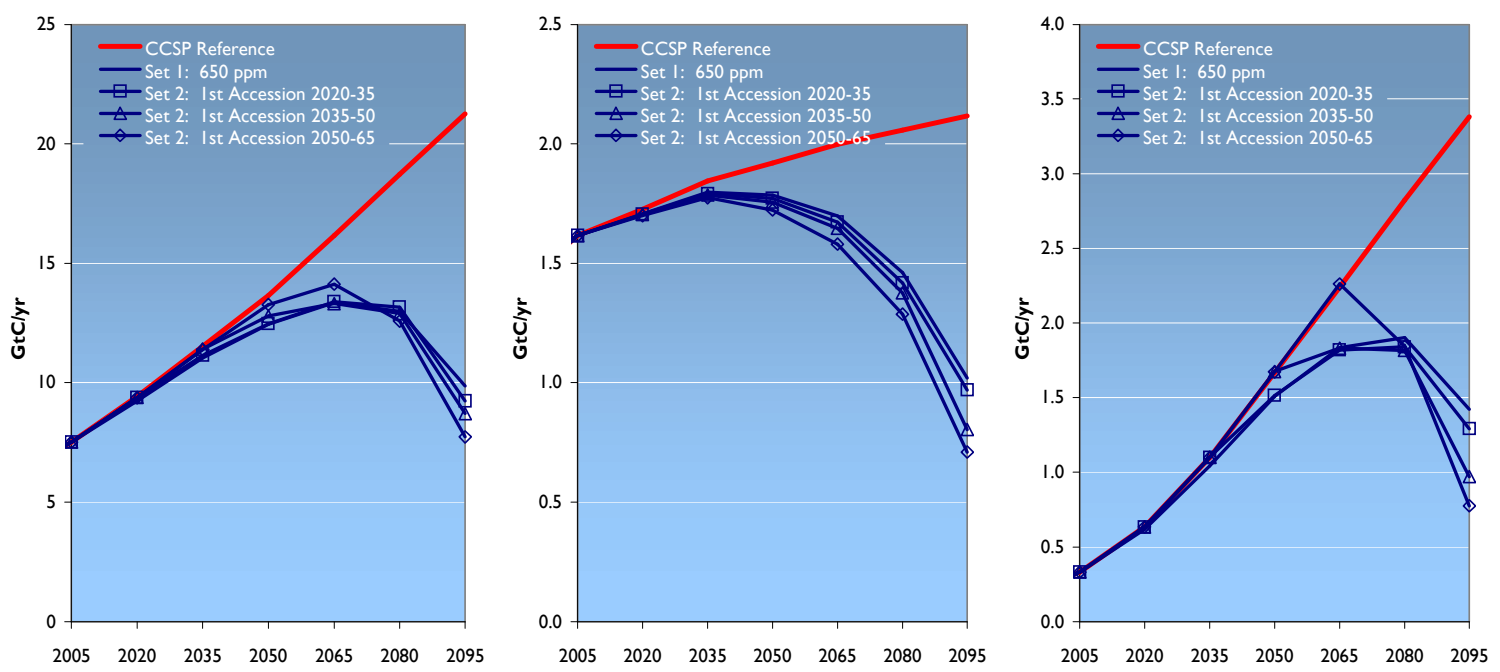

Figure 5.4. Set 2 Stabilization at $650 \mathrm{ppmv}$ - Global, U.S., and India Emissions 

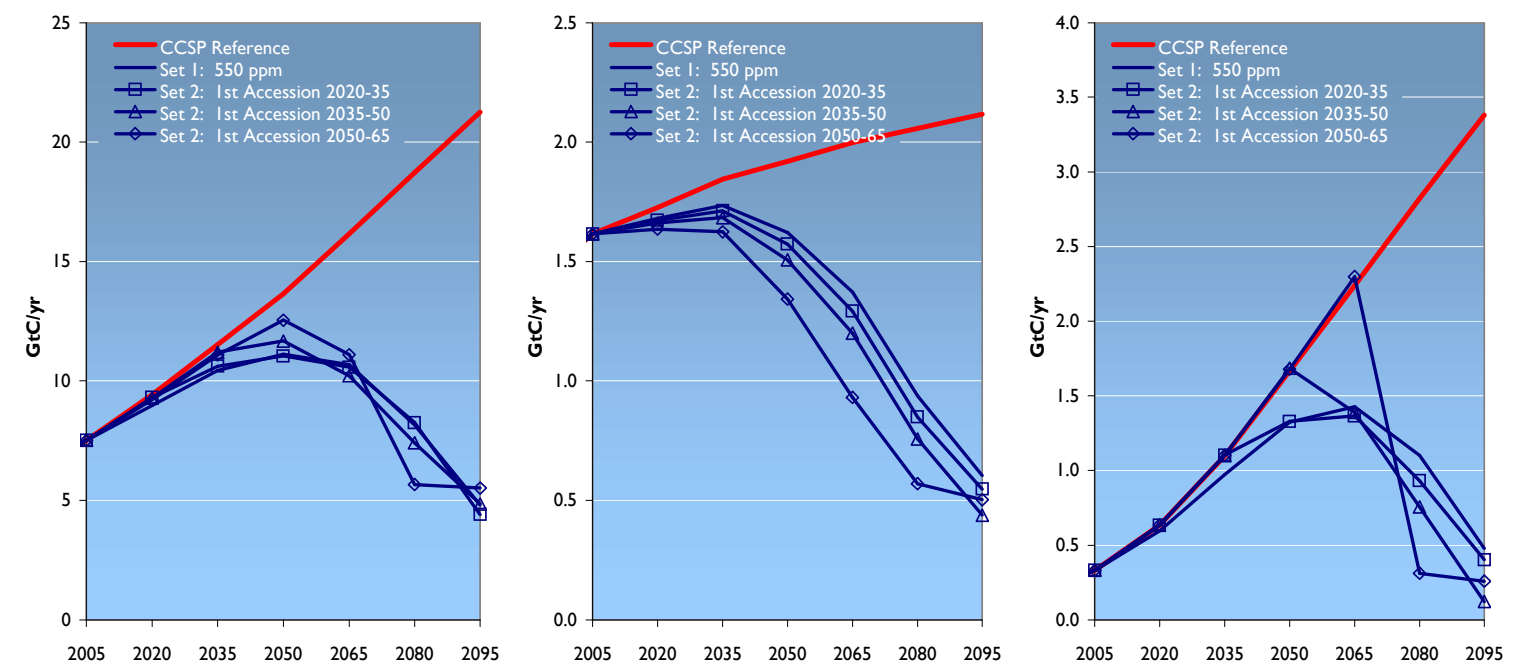

Figure 5.5. Set 2 Stabilization at 550 ppmv—Global, U.S., and India Emissions
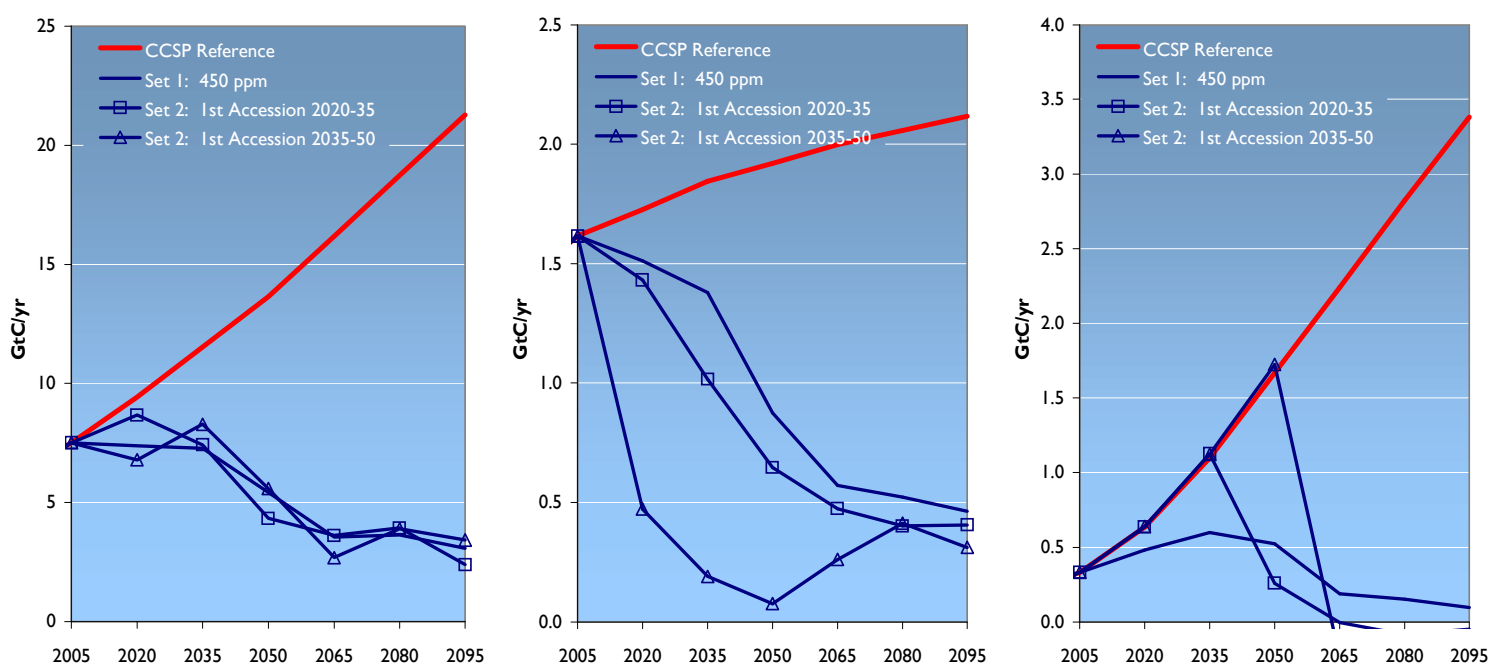

Figure 5.6. Set 2 Stabilization at 450 ppmv—Global, U.S., and India Emissions

Set 3: Heterogeneous Regimes. Accession need not imply a common value of carbon at the point of initial entrance into the coalition of regions taking mitigation actions. Set 3 explores the implication of a regime in which the Annex I countries see a common carbon price that follows a HPW structure, but one in which the carbon price trajectory for each late entrant is unique and lower than the Annex I coalition price. This regime is less efficient than Set 2 from the perspective of "when" and "where" flexibilities; however, it avoids the shock associated with later accession to an emissions mitigation regime whose price has risen substantially relative to its initial level.

The structure of the hypothesized heterogeneous regime is such that the U.S. carbon price is always above the first-best price and India's carbon price remains below the first-best price until late in the century (Figure 5.7 through Figure 5.9). Furthermore, the price of carbon in the U.S. is dramatically higher than in the first-best scenarios reaching more than $\$ 1000$ per ton by the end of the century when $\mathrm{CO}_{2}$ concentrations are stabilized at 550 ppmv. Prices are multiple thousands of dollars per ton by midcentury in the 450 ppmv case. 

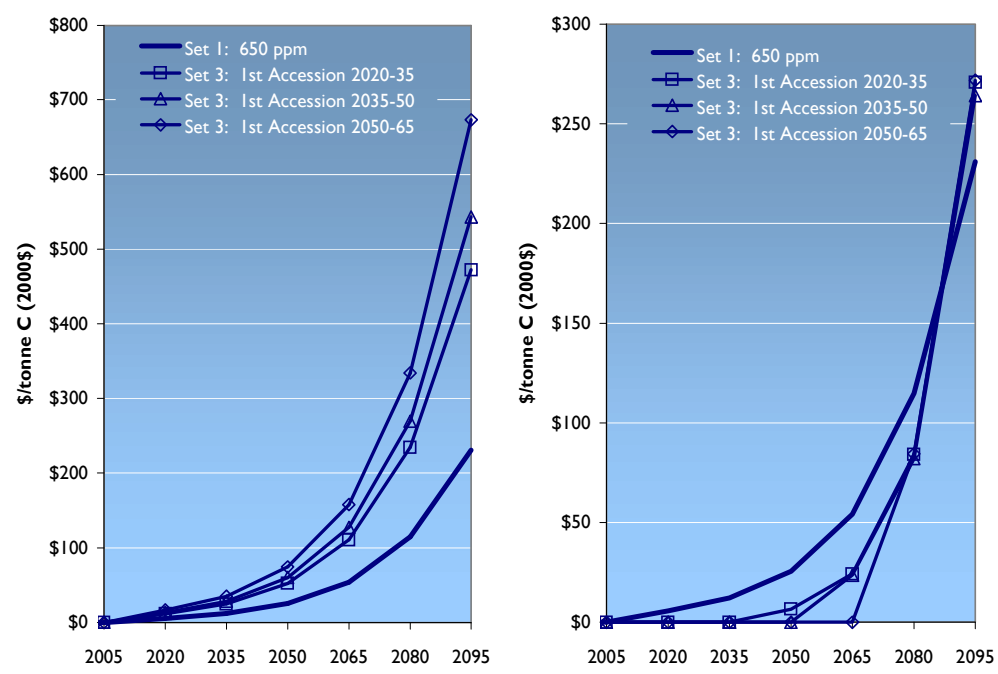

Figure 5.7. Set 3 Regional Carbon Prices 650 ppmv - Annex 1 and India
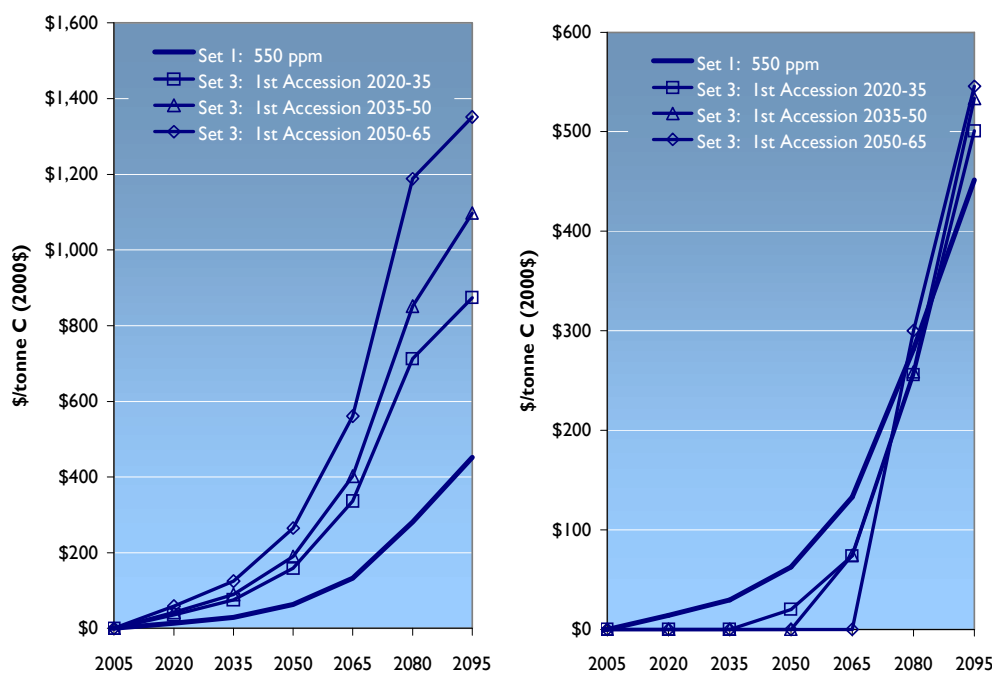

Figure 5.8. Set 3 Regional Carbon Prices 550 ppmv - Annex 1 and India 

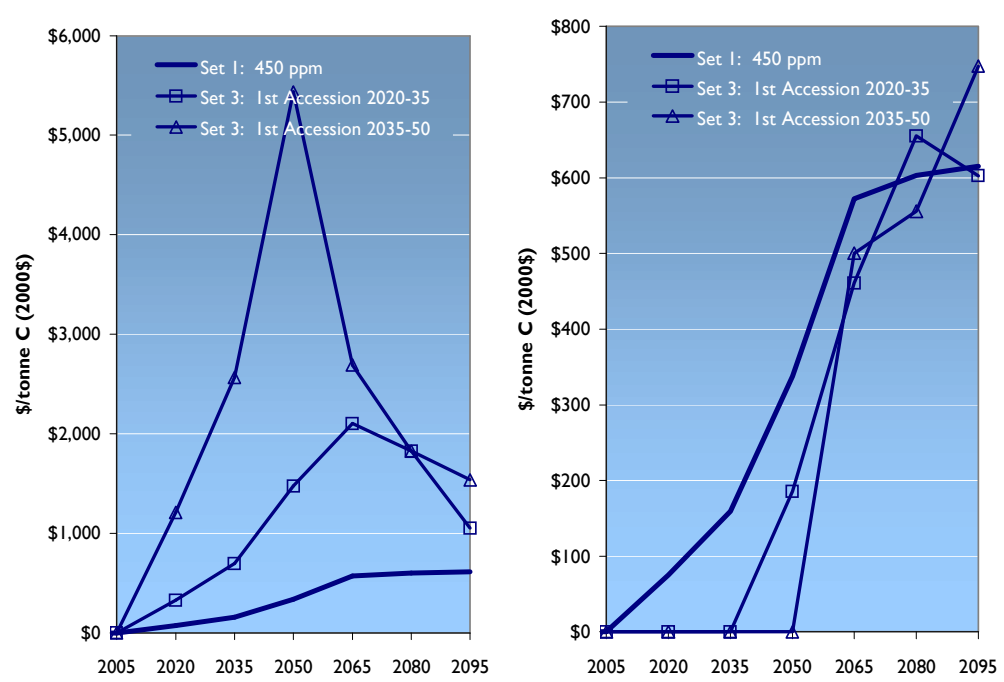

Figure 5.9. Set 3 Regional Carbon Prices 450 ppmv - Annex 1 and India

Although the global 550 ppmv $\mathrm{CO}_{2}$ emissions trajectory in Set 3 is similar to the global 550 ppmv emissions trajectory under first-best policy conditions, there are dramatic differences at the regional scale (Figure 5.10 and Figure 5.12). (There is some displacement of emissions reductions to the future in Set 3 as compared to first-best.) The U.S. emissions decline dramatically faster in Set 3 than under first-best policy conditions. In Set 3, with non-Annex I accession delayed to 2035 or later, U.S. emissions are forced to become negative before the end of the century.

The Set 3450 ppmv cases are even more dramatic. Again, there is little difference in the global emissions trajectories between the first best and Sets 2 and 3. However, at the regional scale, the U.S. emissions reductions exceed 50 percent by the year 2020 with any delay in non-Annex I accession even to 2020. Aggregate Annex-I regions reduce emissions 40 percent relative to 2005 for a delay in accession to 2020. As with Set 2, stabilization is physically infeasible if accession is delayed past 2050.
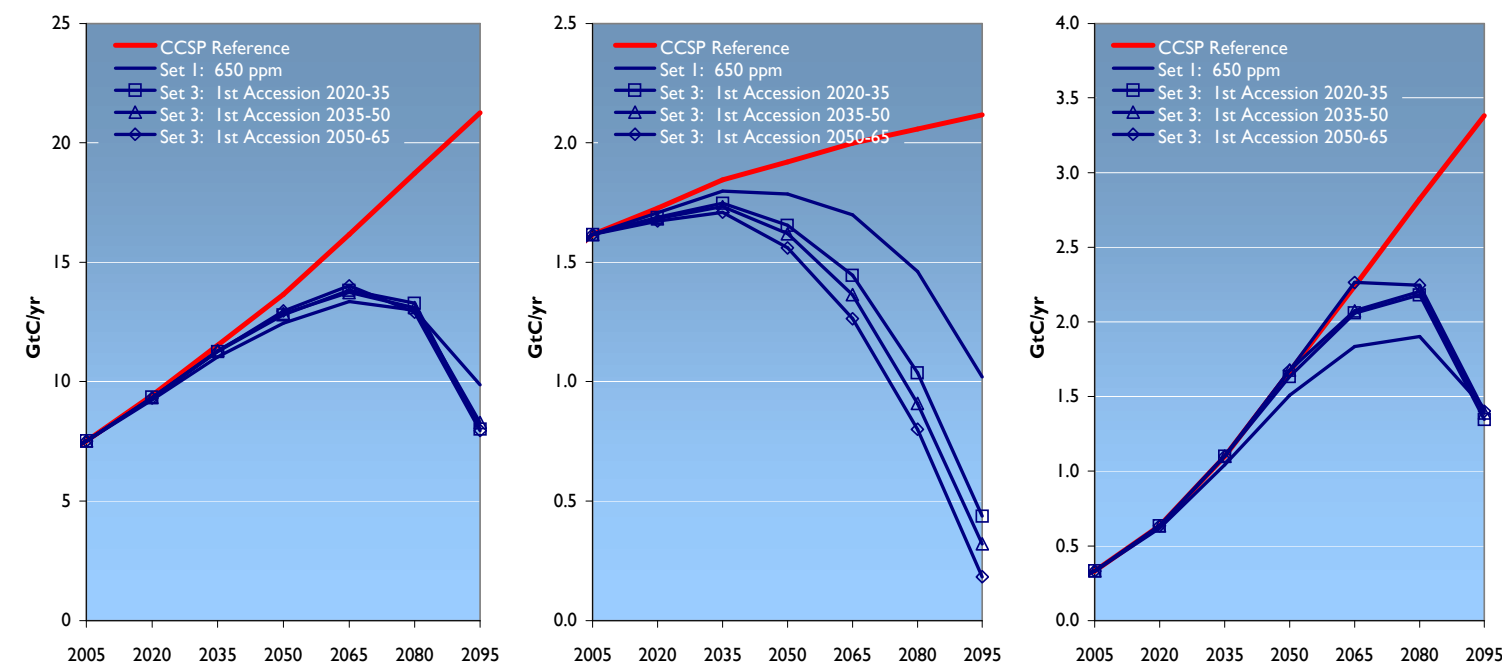

Figure 5.10. Set 3 Stabilization at 650 ppmv—Global, U.S., and India Emissions 

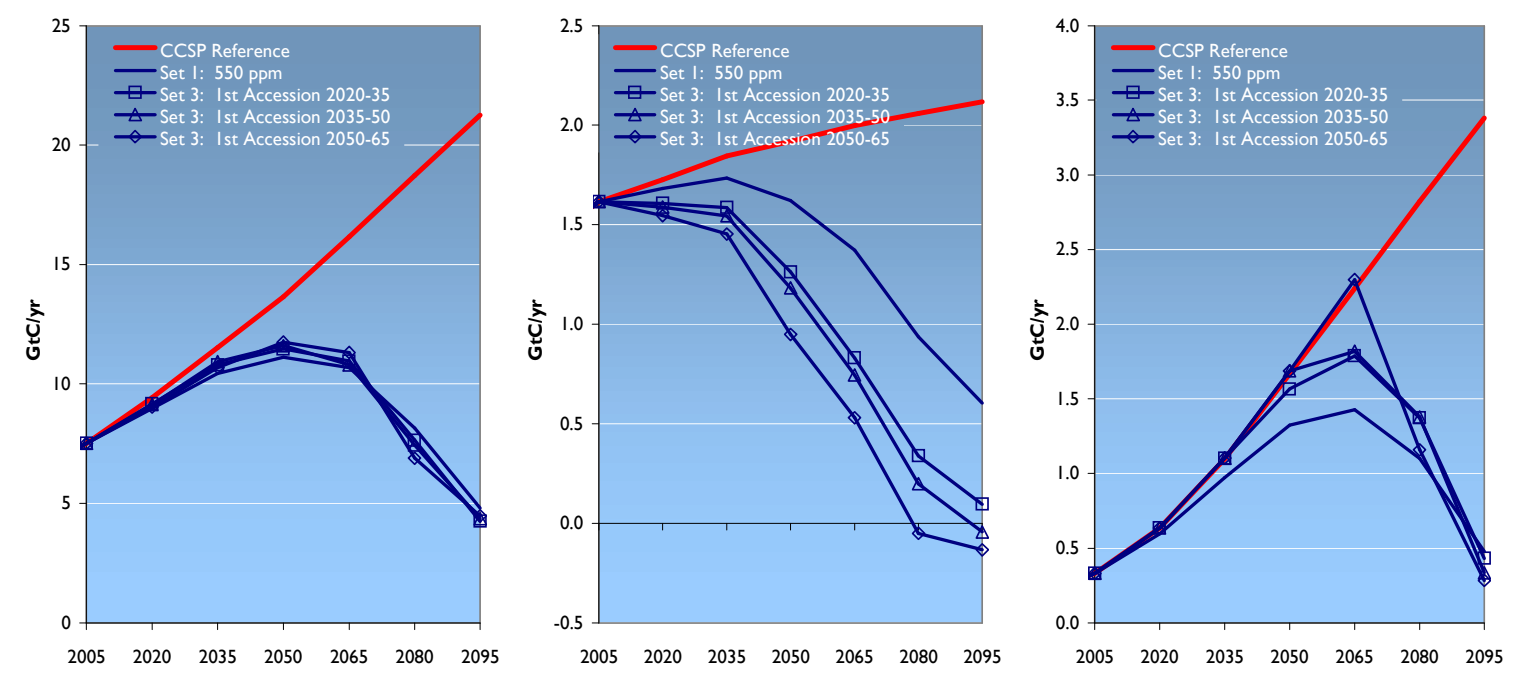

Figure 5.11. Set 3 Stabilization at 550 ppmv—Global, U.S., and India Emissions
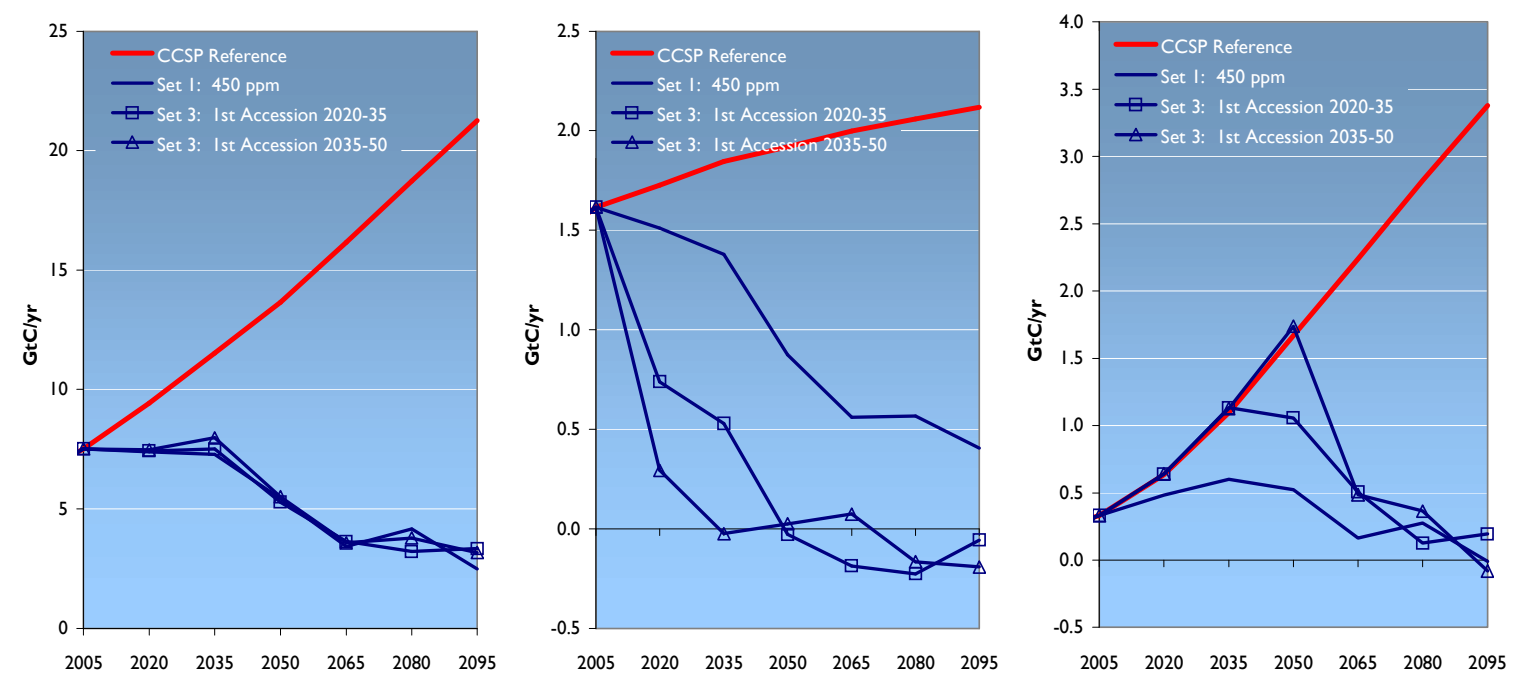

Figure 5.12. Set 3 Stabilization at 450 ppmv—Global, U.S., and India Emissions 


\subsection{The Distribution of Costs Associated with Delayed Accession}

Inefficiencies in the carbon market increase the economic costs of stabilizing $\mathrm{CO}_{2}$ concentrations. Delays in accession are one example. For any environmental goal, the greater the delay in accession, the lower the efficiency, and therefore the greater total cost to society of achieving the environmental goal. ${ }^{1}$

Table 6.1. Percentage Increase in Total Social Cost of Stabilization at Alternative Levels of Atmospheric $\mathrm{CO}_{2}$ Relative to First Best ${ }^{2}$

\begin{tabular}{||c|c|c|c||}
\hline Scenario & $\mathbf{4 5 0} \mathbf{p p m v}$ & $\mathbf{5 5 0} \mathbf{p p m v}$ & $\mathbf{6 5 0} \mathbf{p p m v}$ \\
\hline \hline First Best & $100 \%$ & $100 \%$ & $100 \%$ \\
\hline 2020 Set 2 & $28 \%$ & $12 \%$ & $8 \%$ \\
\hline 2035 Set 2 & $265 \%$ & $28 \%$ & $23 \%$ \\
\hline 2050 Set 2 & Infeasible & $65 \%$ & $40 \%$ \\
\hline 2020 Set 3 & $112 \%$ & $47 \%$ & $36 \%$ \\
\hline 2035 Set 3 & $394 \%$ & $69 \%$ & $54 \%$ \\
\hline 2050 Set 3 & Infeasible & $139 \%$ & $83 \%$ \\
\hline
\end{tabular}

Three factors influence explored here influence the total discounted costs of stabilization: (1) the length of delay ("when" flexibility), (2) the degree to which participating countries equalize marginal abatement costs ("where" flexibility), and (3) the stabilization level. The cost effects of delay are isolated in the Set 2 scenarios (Table 6.1). It is no surprise that the cost of delayed accession increases with the length of delay; that is, the longer the first accession is delayed, the greater the incremental cost for reaching any environmental goal. After all nations join the emissions mitigation regime, perfect "where" flexibility is established and that source of incremental social cost is eliminated. However, as noted earlier, late entrants to mitigation may face difficulties in the form of carbon price "shock" associated with later accession to a regime whose carbon price had been escalating along a HPW path.

The incremental influence of inefficiencies in "where" flexibility is captured by the Set 3 scenarios. These scenarios eliminate the price shock from joining the coalition of emissions-reducing countries, which could be seen as a desirable characteristic of a global policy regime. However, they have the effect of pushing non-Annex 1 emissions reductions even further into the future for any given set of accession dates. The distinction between the Set 2 and Set 3 scenarios can be posed from a policy perspective as a tradeoff between accession date and the ease of accession: these two inefficiencies can be traded off to meet a given cost goal. For example, meeting a 450 ppmv stabilization limit with first accession in 2020 and gradual entrance into the coalition is roughly equivalent to meeting this same limit with first accession between 2020 and 2035 but assuming immediate entrance into the coalition. Meeting a 550 ppmv stabilization limit stabilization limit with first accession in 2035 and gradual entrance into the coalition is roughly equivalent to meeting this same limit with first accession in 2050.

The cost impacts of delay are increasingly potent the tighter is the stabilization level. That is to say, the percentage increases in costs relative to first-best from the introduction of "where" and "when"

\footnotetext{
${ }^{1}$ The regional or national effects of stabilization are a function of the distributional mechanisms embodied in any policy, so imperfections may or may not increase the economic impacts to specific countries or regions.

${ }^{2}$ Global costs represent the discounted value of costs from 2005 through 2095 under a 5\% discount rate.
} 
inefficiencies are higher the more stringent is the constraint. Again, this is a result of the inherent physical limitations to flexibility that arise from the operation of the carbon cycle. As emissions reductions are reduced or delayed in non-Annex 1 countries, the result is that Annex 1 countries must move to increasingly higher marginal cost mitigation measures, increasing costs. The limits to total emissions also affect these marginal costs. Delays in the 450 ppmv scenarios push Annex 1 countries into increasingly high near-term marginal cost regimes.

Delayed accession and gradual entrance of non-Annex I regions both reduce the proportion of emissions mitigation costs that are borne in non-Annex I regions (Table 6.2). Note that these costs represent only the portion of mitigation costs borne in each of these countries; they do not represent the costs to the countries themselves, which would depend, for example, on the burden-sharing scheme in a cap-and-trade system or explicit transfer payment schemes in other policy structures. ${ }^{3}$

Table 6.2. Fraction of Total Social Cost of Stabilization at Alternative Levels of Atmospheric $\mathrm{CO}_{2}$ Borne by Non-Annex I Regions

\begin{tabular}{||c|c|c|c||}
\hline \hline Year of First Accession & $\mathbf{4 5 0} \mathbf{p p m v}$ & $\mathbf{5 5 0} \mathbf{p p m v}$ & $\mathbf{6 5 0} \mathbf{p p m v}$ \\
\hline \hline First Best & $66 \%$ & $72 \%$ & $73 \%$ \\
\hline 2020 Set 2 & $60 \%$ & $69 \%$ & $71 \%$ \\
\hline 2035 Set 2 & $35 \%$ & $65 \%$ & $68 \%$ \\
\hline 2050 Set 2 & N/A & $59 \%$ & $65 \%$ \\
\hline 2020 Set 3 & $26 \%$ & $38 \%$ & $42 \%$ \\
\hline 2035 Set 3 & $17 \%$ & $34 \%$ & $36 \%$ \\
\hline 2050 Set 3 & N/A & $28 \%$ & $31 \%$ \\
\hline
\end{tabular}

Ironically, in Set 2, delays in accession shift the burden away from non-Annex I regions and toward Annex I regions, but the induced inefficiencies actually result in higher non-Annex I present discounted total costs than under first-best policy conditions. However, those costs are only encountered after the accession. In the near term, delays in accession allow non-Annex I regions to avoid emissions mitigation costs all together. Therefore, Annex I discounted total costs rise even more. Set 3 is another consideration. While global total costs rise still higher than in Set 2, delays in accession and lower-marginal carbon prices lead to greater reductions in the share of global total costs borne by non-Annex I in its emissions mitigation. Total present discounted non-Annex I emissions mitigation costs are also reduced in all of the cases analyzed here.

\footnotetext{
${ }^{3}$ This analysis assumed that all regions of the world imposed a price on themselves to achieve emissions mitigation. There were no transfer payments, as would occur in a "cap-and-trade" regime. As noted earlier, emissions mitigation would be similar in both a "cap-and-trade" regime and a carbon price regime. However, the "cap-and-trade" regime assigns property rights, which may be different from emissions in the mitigation regime. Such differences would introduce associated transfer payments, whose magnitude and direction of transfer depend entirely on the allocation of emissions rights.
} 


\subsection{Final Considerations}

Second-best worlds are just that: second best. By definition, stabilization in economically inefficient regimes imposes a greater burden on global society to achieve the same environmental benefit as economically efficient regimes. This paper has explored the implications of two types of inefficient hypothetical international protocols that would result in the stabilization of $\mathrm{CO}_{2}$ concentrations. These delays have nonlinear implications for stabilization costs in both the degree and character of delay, and the stabilization level.

Stabilization at a concentration of $450 \mathrm{ppmv}$ is fundamentally different than stabilization at higher $\mathrm{CO}_{2}$ concentrations. The $450 \mathrm{ppmv}$ concentration is so close to present concentrations, and demands for fossil fuels rise so rapidly in non-Annex I nations, that delays in accession have severe consequences for regions in the control coalition. Under the assumptions in these scenarios, a reduction of more than 85 percent relative to 2005 annual $\mathrm{CO}_{2}$ emissions in 2050 by Annex I nations is consistent with stabilization of $\mathrm{CO}_{2}$ at $450 \mathrm{ppmv}$ if non-Annex I regions accede into a heterogeneous control regime after 2020. Still more severe reductions are required if non-Annex I regions delay longer. Much greater latitude is available in the 550 and 650 ppmv stabilization regimes; that is, emissions mitigations associated with 550 or 650 ppmv stabilization regimes require far less-stringent emissions mitigation by 2050, and the effect of delayed accession has a far lesser effect on Annex I emissions mitigation.

A fundamental premise of delayed accession is that regions will see different effective carbon prices, a premise that has been examined in various ways in this paper. The scenarios in this paper have demonstrated potentially dramatic increases in carbon prices in Annex I regions, resulting from delayed accession. This raises the question of whether it is plausible to envision a world, as this paper has done in some of its scenarios, in which the Annex I countries conduct mitigation with carbon prices in excess of $\$ 1000$ dollars/tonne, while the non-Annex I countries take no mitigation action whatsoever. This sort of asymmetry would certainly give rise to internal pressures in the participating countries to take advantage of opportunities for low-cost reductions in nonparticipating countries. One role of the Clean Development Mechanism of the Kyoto Protocol was to provide a mechanism by which carbon price signals could be transmitted to non-Annex I regions prior to their accession. In the real world, other mechanisms might be expected to be developed to cushion both the shock of accession and the internal pressures that would develop in participating nations due to the asymmetric requirements among nations.

This paper has not fully explored the domain of $\mathrm{CO}_{2}$ concentration limits in the context of second-best international control regimes, and much work remains to be done in this area. Future work might explore interactions between domestic inefficiencies and the international regimes, and it might explore the implications of various mechanisms for minimizing asymmetry between regions. Future work also needs to begin the systematic exploration of second-best regimes that "over shoot" their concentration ceiling. For example, exceeding an atmospheric $\mathrm{CO}_{2}$ concentration of $450 \mathrm{ppmv}$ does not necessarily mean it is lost forever. However, overshoots come with their own costs and that domain needs to be explored systematically. 



\subsection{References}

Brenkert A, S Smith, S Kim, and H Pitcher. 2003. Model Paperation for the MiniCAM. PNNL-14337, Pacific Northwest National Laboratory, Richland, Washington.

Clarke, L, J Edmonds, H Jacoby, H Pitcher, J Reilly, and R Richels. 2007a. Scenarios of Greenhouse Gas Emissions and Atmospheric Concentrations. Sub-report 2.1A of Synthesis and Assessment Product 2.1 by the U.S. Climate Change Science Program and the Subcommittee on Global Change Research. U.S. Department of Energy, Office of Biological \& Environmental Research, Washington, D.C.

Clarke L., J. Edmonds, S. Kim, J. Lurz, H. Pitcher, S. Smith, M. Wise. 2007b. Documentation for the MiniCAM CCSP Scenarios. Battelle Pacific Northwest Division Technical Report, PNNL-16735.

Edmonds, JA, DW Barns, and M Ton. 1993a. "The Regional Costs and Benefits of Participation in Alternative Hypothetical Carbon Coalitions." In Reducing Carbon Emissions from the Energy Sector: Cost and Policy Options, eds Gaskins, D. and J. Weyant. Stanford Press, Stanford, California.

Edmonds, JA, DW Barns, and M Ton. 1993b. "Carbon Coalitions: The Cost and Effectiveness of Energy Agreements to Alter Trajectories of Atmospheric Carbon Dioxide Emissions." In International Workshop on Costs, Impacts, and Possible Benefits of $\mathrm{CO}_{2}$ Mitigation, eds Y. Kaya, N. Nakicenovic, W.D.

Nordhaus, and F.L. Toth, pp. 291-314. June 1993, Laxenburg, Austria. The Institute for Applied Systems Analysis (IIASA), Laxenburg, Austria.

Edmonds, J. and J. Reilly. 1985, Global Energy - Assessing the Future, Oxford University Press.

Edmonds, J., and M. Wise. 1998. "The Economics of Climate Change: Building Backstop Technologies And Policies To Implement The Framework Convention On Climate Change," Energy \& Environment. 9(4):383-397.

Hotelling, H. 1931. "The Economics of Exhaustible Resources." Journal of Political Economy 39: 137-175.

IPCC, 2001: Climate Change 2001:Mitigation. The Contribution of Working Group III to the Third Assessment Report of the Intergovernmental Panel on Climate Change, Intergovernmental Panel on Climate Change, Cambridge University Press, Cambridge, U.K.

Kheshgi, H, SJ Smith, and J Edmonds. 2005. "Emissions and Atmospheric $\mathrm{CO}_{2}$ Stabilization: Long-term Limits and Paths." PNNL-SA-38439. In Mitigation and Adaptation Strategies for Global Change, Climate Change and Environmental Policy 10: 213-220.

Kim SH, JA Edmonds, J Lurz, SJ Smith, and MA Wise. 2006. "The ObjECTS: Framework for Integrated Assessment: Hybrid Modeling of Transportation.” The Energy Journal (Special Issue No. 2 2006):63.

Peck, SC and YH Wan. 1996. "Analytic Solutions of Simple Greenhouse Gas Emission Models." Chapter 6 of Economics of Atmospheric Pollution, eds EC Van Ierland and K Gorka. Springer Verlag, New York. 
Richels, R., J. Edmonds, H. Gruenspecht, and T. Wigley. 1996. "The Berlin Mandate: The Design of Cost-Effective Mitigation Strategies." Climate Change: Integrating Science, Economics and Policy, CP96-1:29-48. N. Nakicenovic, W.D. Nordhaus, R. Richels, and F.L. Toth (eds.), International Institute for Applied Systems Analysis, Laxenburg, Austria (20pp).

Rose, A, B Stevens, J Edmonds, and M Wise. 1998. "International Equity and Differentiation in Global Warming Policy.” Environmental Resource Economics 12(25-51): 26.

United Nations. 1992. Framework Convention on Climate Change. United Nations, New York.

Weyant, J. and J. Hill, 1999, Introduction and Overview - Special Issue on the Costs of the Kyoto Protocol: A Multi-Model Evaluation, the Energy Journal.

Wigley, TML, R Richels, and J Edmonds. 2006. "Overshoot Pathways to $\mathrm{CO}_{2}$ Stabilization in a Multi-gas Context." In Human-Induced Climate Change: An Interdisciplinary Perspective, eds. M Schlesinger, FC de la Chesnaye, H Kheshgi, CD Kolstad, J Reilly, JB Smith and T Wilson. Cambridge University Press, United Kingdom. 